\title{
ATMOSPHERIC METHANE, RECORD FROM A GREENLAND ICE CORE OVER THE LAST 1000 YEAR
}

\author{
T. Blunier*, J. A Chappellaz ${ }^{+}$, J. Schwander*, J.-M. Barnola ${ }^{+}$T. Desperts ${ }^{+}$, B Stauffer*, D. Raynaud ${ }^{+}$
}

\begin{abstract}
The atmospheric methane concentration in ancient times can be reconstructed by analysing air entrapped in bubbles of polar ice sheets. We present results from an ice core from Central Greenland (Eurocore) covering the last 1000 years. We observe variations of about $70 \mathrm{ppbv}$ around the mean pre-industrial level, which is confirmed at about 700 ppbv on a global average According to our data, the beginning of the anthropogenic methane increase can be set between 1750 and 1800 Changes in the oxidizing capacity of the atmosphere may contribute significantly to the pre-industrial methane concentration variations, but changes in methane emissions probably play a dominant role. Since methane release depends on a host of influences it is difficult to specify clearly the reasons for these emission changes. Methane concentrations correlate only partially with proxydata of climatic factors which influence the wetland release (the main source in pre-industrial times). A good correlation between our data and a population record from China suggests that man may already have influenced the $\mathrm{CH}_{4}$-cycle significantly before industrialisation.
\end{abstract}

\section{Introduction}

Methane is a radiatively and chemically active trace gas of the earth's atmosphere. Its atmospheric concentration has been measured continuously and directly since 1978 and shows an average increase of 08 to $1 \%$ per year [Blake and Rowland, 1988] with a slow-down during the most recent years [Steele et al., 1992]. There is strong evidence that the increase is caused by the increasing agricultural and industrial activities of the growing human population. Future trends of atmospheric $\mathrm{CH}_{4}$ depend on the strength of the anthropogenic sources, the sinks as well as on the potential natural feedbacks of the greenhouse warming on the $\mathrm{CH}_{4}$ cycle. One can learn about natural feedbacks by looking at the past variations of the atmospheric $\mathrm{CH}_{4}$ and their links with natural climatic changes. At present, the most reliable means to investigate the evolution of the atmospheric trace gases in the past is the analysis of air entrapped in the bubbles of polar ice sheets. Previous ice core studies which focused on the past atmospheric $\mathrm{CH}_{4}$ trend have revealed that over the last 1000 years, the $\mathrm{CH}_{4}$ background was mostly around $700 \mathrm{ppbv}$, that is only about $40 \%$ of its present-day level [Rasmussen and Khalil, 1984; Stauffer et al., 1985; Raynaud et al., 1988; Etheridge et al., 1992]. Orily during the last 200-300 years did the $\mathrm{CH}_{4}$ mixing ratio increase to its present-day level of about $1700 \mathrm{ppbv}$. Fluctuations of up to $50 \mathrm{ppbv}$ around the 700 ppbv "natural" level were suggested [Khalil and

\footnotetext{
* Physics Institute, University of Bern, Switzerland.

+ CNRS Laboratoire de Glaciologie, Grenoble, France.
}

Copyright 1993 by the American Geophysical Union.

Paper number 93GL02414

0094-8534/93/93GL-02414\$03.00
Rasmussen, 1989] but were not clearly resolved due to the large scatter of the data and problems in dating the air samples. This paper presents new results from two laboratories with an analytical precision and time resolution which allow the observation of features not seen before on the time scale of the last 1000 years.

In the framework of the Eurocore project, in 1989, an ice core of 304 meters was drilled electromechanically at Summit in Central Greenland $\left(72.58^{\circ} \mathrm{N}, 37.64^{\circ} \mathrm{W}\right.$; mean annual temperature: $-32^{\circ} \mathrm{C}$, mean accumulation rate: $209 \mathrm{~kg} / \mathrm{m}^{2} / \mathrm{yr}$ ). The absence of any drilling fluid and the low temperature make the core suitable for gas measurements. The core was dated with an accuracy of \pm 2 years by combining seasonal variations of $\delta \mathrm{D}$ and $\delta^{18} \mathrm{O}$ with electric conductivity measurements and chemical data. Acid layers of volcanic eruptions were used as timemarkers for cross-checking. The age difference between the ice and the mean age of the enclosed air is about 210 years. Due to the diffusive mixing in the firn the air in the bubbles has not a discrete age but an age distribution with a standard deviation of about 7 years [Schwander et al., 1993].

\section{Experiments}

Since methane does not interact chemically with water, both dry and melt extraction methods are applicable. The measurements presented were carried out in two laboratories In Grenoble a melt extraction technique was used and in Bern the gas was extracted with a dry extraction method.

For the melt extraction method an ice sample of about $40 \mathrm{~g}$ is placed in a glass vessel sealed with vacuum grease. The air surrounding the sample is evacuated, then the ice is melted. After that, the meltwater is slowly refrozen from the bottom, expelling close to $100 \%$ of the dissolved air. After refreezing, the extracted gas is expanded in an extraction line and injected in a gas chromatograph (GC) (Varian 3300) equipped with a flame ionization detector (FID). The extracted air is used for three injections. The measured methane concentrations have to be corrected due to a contamination in the extraction chamber The correction is determined by calibration with standard gas added to gas-free ice. The overall accuracy estimated from calibration analyses (95\% confidence interval, excluded the uncertainty due to the standard gas) is $\pm 40 \mathrm{ppbv}$ [Raynaud et al. 1988]. The system is calibrated using an air standard (Air Liquide) containing $1200 \pm 100$ ppbv of $\mathrm{CH}_{4}$.

The dry extractions have been performed with a newly developed milling device [Fuchs et al., 1993]. 10 to $15 \mathrm{~g}$ of ice are sealed in the extraction chamber which is continuously flushed with helium. When the air in the chamber is entirely replaced by helium, the ice is milled with a rotary cutter. The helium carries the gases escaping from the opened bubbles to a cryofocusing device (Porapack Q column, cooled to below $-170^{\circ} \mathrm{C}$ by liquid nitrogen) where they are stored until the injection into the GC (Hewlett Packard 5880 A, equipped with a FID) through thermal desorption. For calibration a standard gas with $980 \pm 30 \mathrm{ppbv}$ (Messer Griessheim) of 
$\mathrm{CH}_{4}$ is used. To estimate the analytical accuracy we carried out a calibration series by introducing standard gas into the mill in order to approximate a real extraction. From this series the $95 \%$ confidence interval for an analyses is \pm 28 ppbv (excluding the uncertainty due to the standard gas).

An independent check of the above-mentioned precision estimates is to look at the reproducibility of measurements performed at the same depth level in the ice. Samples on a given depth level are separated at most by $55 \mathrm{~cm}$, corresponding to a difference of age of about 2 years and hence a negligible difference in composition of the air-bubbles. In both laboratories, generally two samples were analysed at each depth level (Table 1). From the variance of the results we calculate mean $95 \%$ confidence intervals for single data points from each laboratory. We find $\pm 40 \mathrm{ppbv}$ for Grenoble and $\pm 20 \mathrm{ppbv}$ for Bern. This is within the statistical variation in good agreement with the analytical precision indicated above.

TABLE 1: Methane concentrations versus depth and gas age:

\begin{tabular}{|c|c|c|c|c|c|c|c|c|}
\hline \multirow[t]{2}{*}{$\begin{array}{c}\text { Depth } \\
\text { [m] }\end{array}$} & \multirow[t]{2}{*}{$\begin{array}{c}\text { Gas age } \\
\text { yr } A D\end{array}$} & \multicolumn{3}{|c|}{$\begin{array}{c}\text { Bern } \\
\mathrm{CH}_{4}[\mathrm{ppbv}]\end{array}$} & \multirow[t]{2}{*}{$\begin{array}{c}\text { Depth } \\
{[\mathrm{m}]}\end{array}$} & \multirow[t]{2}{*}{$\begin{array}{c}\text { Gas age } \\
\text { yr AD }\end{array}$} & \multicolumn{2}{|c|}{$\begin{array}{c}\text { Grenoble } \\
\mathrm{CH}_{4} \text { [ppbv] }\end{array}$} \\
\hline & & $\mathrm{C} 1$ & $\mathrm{C} 2$ & C3 & & & K1 & $\mathrm{K} 2$ \\
\hline 89.2 & 1907 & 996 & 991 & 980 & 09.0 & 1 & 1030 & 968 \\
\hline 99.3 & 1864 & 870 & 862 & & & & 859 & 896 \\
\hline 110.1 & 1817 & 808 & 798 & & 104.5 & 1842 & 812 & 818 \\
\hline 1189 & 1775 & 803 & 796 & & 11 & 1 & 764 & 754 \\
\hline 128.8 & 1734 & 753 & 763 & & & & 755 & 765 \\
\hline 138.7 & 1691 & 738 & 773 & & 129 & 1733 & 729 & 726 \\
\hline 148.8 & 1651 & 740 & 766 & & 17 & & 770 & 774 \\
\hline 158.4 & 1605 & 730 & 743 & & & & 714 & 750 \\
\hline 168.8 & 1555 & 763 & 760 & & 15 & 10 & 690 & 722 \\
\hline 178.2 & 1510 & 761 & 726 & & 16 & & 760 & 781 \\
\hline 188.4 & 1466 & 690 & 710 & & 178.6 & 15 & 740 & 728 \\
\hline 216.1 & 1335 & 692 & 678 & & 188.2 & & 724 & 727 \\
\hline 233.5 & 1254 & 694 & 703 & & 211.5 & 1357 & 700 & 688 \\
\hline 242.9 & 1210 & 743 & 729 & & 219.2 & 1320 & 714 & 749 \\
\hline 252.4 & & 763 & 756 & & 222.7 & 1304 & 703 & 733 \\
\hline 263 & 1114 & 738 & 727 & & 233.7 & 1253 & 693 & 656 \\
\hline 2723 & 1075 & 711 & 725 & & 243 & 1210 & 710 & 774 \\
\hline 283 & 1025 & 722 & 717 & & 251.9 & 1168 & 811 & 752 \\
\hline 292.6 & 974 & 714 & 695 & & & & & \\
\hline
\end{tabular}

Depth: Meters below the surface of 1989. Each of the sets $\mathrm{C} 1-\mathrm{C} 3$ and $\mathrm{K} 1, \mathrm{~K} 2$ consists of results from neighbouring samples. While each of $\mathrm{C} 1-\mathrm{C} 3$ are results from single gaschromatographic analysis of the extracted gas, $\mathrm{K} 1$ and $\mathrm{K} 2$ are mean values from three analyses

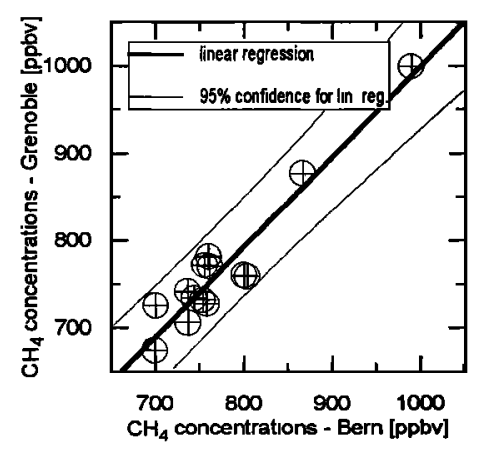

Fig. 1: Methane results obtained at the same depth levels: Comparision between Grenoble and Bern. Solid line: Linear regression. Dashed lines: Limits for the $95 \%$ confidence interval for the regression.
The comparison between the two laboratories was carried out by measurements at the same depth levels and by intercalibrating the standard gases. For each depth level analysed by both laboratories, the mean result from Grenoble is plotted against the mean result from Bern in Figure 1. The linear regression with a slope of $1.03 \pm 0.09$ and the mean difference between data pairs (Bern minus Grenoble values) of $7 \pm 6$ ppbv demonstrate that the equipment in Bern and in Grenoble lead to the same results within the statistical variations. The intercalibration of the standard gases used by the two laboratories reveals an agreement better than $\pm 5 \mathrm{ppbv}$. We assume therefore that the absolute uncertainty of the standard gases used in Bern and in Grenoble corresponds to the lower one of those indicated by the two suppliers, that is $\pm 30 \mathrm{ppbv}$.

\section{Results}

A total of 36 samples at 18 depth levels and 39 samples at 19 depth levels have been analysed in Grenoble and Bern, respectively (Table 1). The samples were spaced at age intervals ranging from 15 to 109 years with an average of 42 years. The composite record from both laboratories is plotted against the mean gas age in Figure 2. The characteristics of the records obtained in the two laboratories are very similar. To illustrate the tendencies more clearly we fit a smoothed spline curve through the combined Bern/Grenoble data set. The very general shape of the $\mathrm{CH}_{4}$ record is consistent with previously published data, with a roughly stable level before $1750 \mathrm{AD}$ and a large increase starting at the beginning of the nineteenth century. On the average, a concentration of 730 ppbv is obtained in the time interval 1000-1750 AD. Considering a pre-industrial interhemispheric gradient of $70 \mathrm{ppbv}$ [Rasmussen \& Khalil, 1984], this tesults in a mean global pre-industrial $\mathrm{CH}_{4}$ concentration of $700 \mathrm{ppbv}$. Apart from this general trend, the present record reveals $\mathrm{CH}_{4}$ variations up to $70 \mathrm{ppbv}$ during pre-industrial times. A concentration maximum occurred around $1150 \mathrm{AD}$, followed by lower $\mathrm{CH}_{4}$ concentrations between 1250 and $1500 \mathrm{AD}$. Around 1500 $\mathrm{AD}$ the concentration increased again to remain relatively constant till $1750 \mathrm{AD}$. According to our data, the beginning of the large and recent anthropogenic methane increase can be set between 1750 and $1800 \mathrm{AD}$.

Rasmussen and Khalil [1984] have published the most complete $\mathrm{CH}_{4}$ record covering the same time interval as ours based on ice core data from Greenland and Antarctica. To compare their record with our results, we reconsidered their record and recalculated the age of the enclosed air by using newer results concerning the enclosure process [Schwander and Stauffer, 1984]. We have increased the data from Antarctica by $10 \%$ in order to account for the interhemispheric gradient [Rasmussen and Khalil, 1984]. A couple of data suspected of being contaminated were eliminated [Khalil and Rasmussen, 1989]. The general trend was extracted by moving averages over each successive 9 data points, following the approach of Khalil and Rasmussen [1989], though there are few results in the period 1200-1500 AD which makes the appropriateness of the running mean approximation questionable. The mean pre-industrial value is the same within the error limits, but the characteristics of the two records are quite different (Figure 2). We consider our record as more reliable because (1) we got more results over the entire interval, (2) the scatter of our results is smaller, and (3) our two 


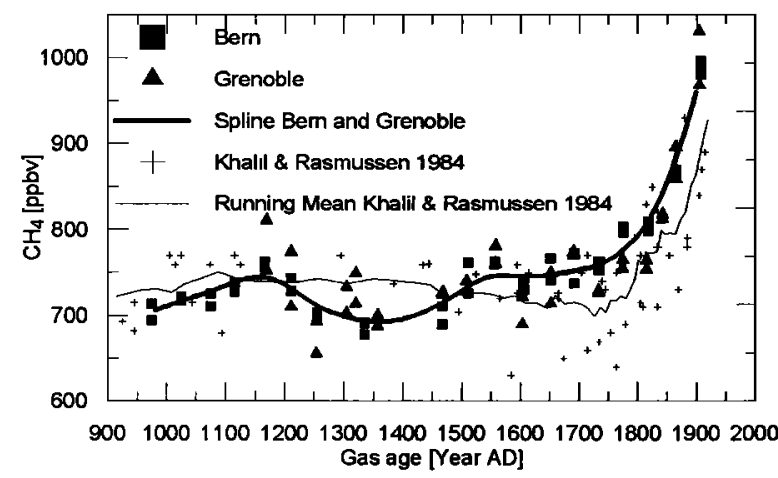

Fig. 2: Methane records versus the mean gas age. Squares and triangles from this study (squares: results from Bern; triangles: results from Grenoble) Thick solid line' Smoothed spline through the Bern and Grenoble data. Crosses: Results from various ice cores [Khalil and Rasmussen, 1984] corrected to Greenland concentration level The mean gas age was recalculated after Schwander and Stauffer [1984]. Thin solid line Running Mean of 9 data points.

laboratories obtained the same characteristics using different analytical methods. We are therefore confident that the detailed pre-industrial trend revealed by our record is significant and reflects variations of the atmospheric $\mathrm{CH}_{4}$ concentration.

\section{Discussion}

In this section we discuss possible causes for the concentration fluctuations observed at Summit in the pre-industrial period between 900 and $1700 \mathrm{AD}$. The methane concentration of the air in the ice reflects changes on a global scale with a higher influence from the northern hemisphere where the majority of the sources is situated. Regional sources are small and thus of minor importance for the air composition in Central Greenland. The difference of $70 \mathrm{ppbv}$ between maximum and minimum $\mathrm{CH}_{4}$ levels corresponds to a $10 \%$ change of the atmospheric burden, that is $190 \mathrm{Tg}$. Assuming steady state conditions, this change (C) is related to the emission change (S) by the equation: $\mathbf{C}=\mathbf{S} \tau$, where $\tau$ is the atmospheric residence time of $\mathrm{CH}_{4}$. Therefore the $70 \mathrm{ppbv}$ variation can be the consequence of a $10 \%$ change of either the sources or the residence time, or a combination of both. The pre-industrial range for $\tau$ is $8-11$ years and the $\mathrm{CH}_{4}$ emissions amounted to about $200 \mathrm{Tg} /$ year [Chappellaz et al., 1993].

The main sink (about 95\%) for methane is the reaction with $\mathrm{OH}$-radicals in the atmosphere. Photochemical models taking into account climate and trace-gas concentration changes suggest a 10 to $30 \%$ decrease of the $\mathrm{OH}$ concentration from the Last Glacial Maximum to the Pre-Industrial Holocene [Thompson, 1992]. The pre-industrial changes in climatic parameters (temperature, trace gases) amount to about one fifth of the shift from glacial to interglacial conditions. Assuming an approximately linear response of the $\mathrm{OH}$ concentration to climate changes, the pre-industrial variations would give rise to 2 to $6 \%$ change of the $\mathrm{CH}_{4}$ lifetime, explaining 20 to $60 \%$ of the $70 \mathrm{ppbv}$ methane concentration change. The remaining 40 to $80 \%$ would have to be explained by changes in the source intensity.

Methane emissions can vary by natural causes or by changes in man-made emissions. According to pre-industrial budget estimates the main natural sources are wetlands which may cause as much as $75 \%$ of the natural emissions during pre-industrial times [Chappellaz et al., 1993]. A 15\% change of the pre-industrial wetland emission would explain the concentration change of 70 ppbv. Wetland emissions of $\mathrm{CH}_{4}$ depend on many parameters including temperature and water table elevation. The extent of wetlands itself depends essentially on the hydrological balance (precipitation minus evaporation and run off). Therefore climatic fluctuations will have an impact on the wetland source strength both through precipitation and temperature.

Since $75 \%$ of the wetland release [Chappellaz et al , 1993] originates from the northern hemisphere we restrict the following comparison to northern hemispheric temperature records. The majority of the available temperature records [Bradley and Jones, 1992] is quite similar, but there exist also a few records showing a quite different picture. Representative of the general trend, two temperature records, one from lake sediments in Michigan (USA) [Bernabo, 1981] and a chronicle record from Central England [Lamb, 1977] are plotted together with our methane data in Figure 3. One remarkable feature is the correspondence between the high $\mathrm{CH}_{4}$ concentrations and the temperature records at the end of the $12^{\text {th }}$ century, corresponding to the Medieval Warm Époque. However, this climatic event is for instance not observed in northern Sweden [Briffa et al. 1990]. The following climatic event, the Little Ice Age, is clearly seen in the two temperature records of Figure 3 . While at its beginning there is a parallel decrease in methane, the latter rises already around 1500, much before the end of the Little Ice Age. Although there is some indication of a correlation between temperature and $\mathrm{CH}_{4}$ concentration, the lack of a global coverage and the broad regional scatter of temperature data preclude detailed conclusions. Data related to the hydrological balance are even more scanty and will not be discussed here.

The magnitude of anthropogenic $\mathrm{CH}_{4}$ sources is in a first approximation related to the global human population, primarily through the increase of the rice cultivation area and the number of domestic ruminants which may be responsible for around $50 \%$ of the concentration change from pre-industrial times to the present [Khalil et al., 1993]. When comparing the pre-industrial methane record with the development

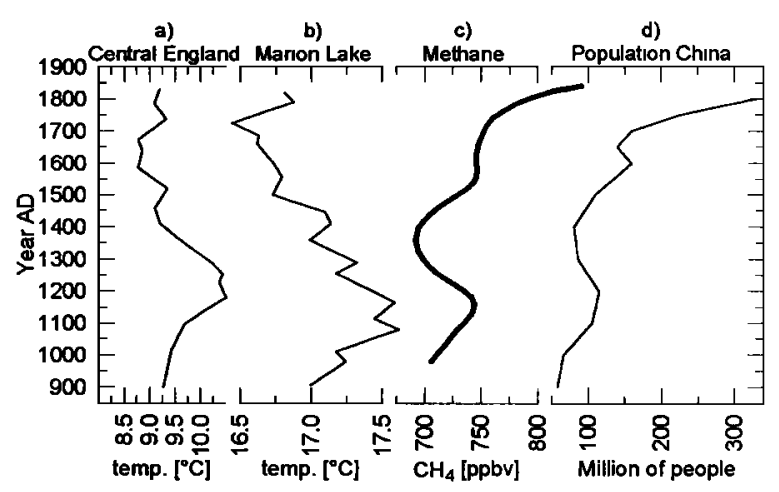

Fig. 3: Comparison between our data and historical records. a) Mean annual temperature of Central England [Lamb, 1977]. b) Growing season temperature from Marion Lake, Michigan [Bernabo, 1981]. c) Methane smoothed spline, this study. d) Population of China [McEvendy and Jones, 1979]. 
of the human population in China, one of the main rice cultivating areas (Figure 3) [McEvendy and Jones, 1979], one can observe that the $\mathrm{CH}_{4}$ concentration variations are surprisingly well correlated with the population fluctuations. The relationship between population and methane emissions from rice cultivation depends on agricultural practices. For the beginning of this century Khalil et al. [1993] report a value of about $35 \mathrm{Tg}$ /year/billion people. Assuming this relation to be valid also for the beginning of the millenium the Chinese population variations alone could explain up to $10 \%$ of a 20 $\mathrm{Tg}$ change in the global emissions between 1200 and 1300 AD. Although data on population and on rice cultivating areas and cultivation practices in ancient times are not very reliable, we think that rice cultivation is likely to contribute to the observed atmospheric concentration change. If so, we have to go further back in time to investigate atmospheric methane concentrations which are totally undisturbed by human.

\section{Conclusion}

Investigations of the atmospheric $\mathrm{CH}_{4}$ changes over the last 1000 years from the Summit ice core confirm the mean pre-industrial level of about $700 \mathrm{ppbv}$ and the recent anthropogenic increase. In addition, we see pre-industrial concentration variations in the range of $70 \mathrm{ppbv}$. 20 to $60 \%$ of these variations can be explained by changes in the oxidizing capacity of the atmosphere. The larger contribution stems from changes in methane emission. Since methane release depends on a host of influences it is difficult to assign reasons for the $70 \mathrm{ppbv}$ pre-industrial variations. Climatic fluctuations on this time scale have probably impacted the largest natural sources, i.e. the wetlands, but the lack of climate proxy data on a global scale preclude a quantitative estimate of this impact. Finally, the role of the pre-industrial anthropogenic sources may have been significant but cannot account for the full amplitude of $\mathrm{CH}_{4}$ variations. Further investigations on historic and proxy climate records are necessary to elaborate a more satisfying scenario describing the interaction of climate, man and the $\mathrm{CH}_{4}$-cycle in the pre-industrial period of this millennium.

Acknowledgement. This work has been supported in France by the EEC (Eurocore project, EPOCH) and by the Programme de l'Environnement du CNRS and in Switzerland through COST 611, the Swiss NSF and the University of Bern. Very useful information was provided by C. Pfister. We thank the Eurocore crew for their fieldwork.

\section{References}

Bernabo, J. C., Quantitative estimates of temperature changes over the last 2700 years in Michigan based on pollen data, Quatern. Res., 15, 143-159, 1981.

Blake, D. R., and Rowland F. S., Continuing wordwide increase in tropospheric methane, 1978 to 1987 , Science, 239, 1129-1131, 1988.

Bradley, R. S., P. D. Jones (Eds.), Climate since A. D. 1500 , 679 pp., Routledge, London and New York, 1992.

Briffa, K. R., T. S. Bartholin, D. Eckstein, P. D. Jones, W. Karlén, F. H. Schweingruber and P. Zetterberg, A 1400- year tree-ring record of summer temperatures in Fennoscandia, Nature, 346, 434-439, 1990.

Chappellaz, J. A., and I. Y. Fung and A. M. Thompson, The atmospheric $\mathrm{CH}_{4}$ increase since the Last Glacial Maximum (1). Source estimates, Tellus, 45B, 228-241, 1993.

Etheridge, D. M., G. I. Pearman, P. J. Fraser, Changes in tropospheric methane between 1841 and 1978 from a high accumulation-rate Antarctic ice core, Tellus, 44B, 282294, 1992.

Fuchs, A., J. Schwander and B. Stauffer, A new ice mill allows precise concentration determination of methane and most probably also other trace gases in the bubble air of very small ice samples, $\underline{\mathbf{J}}$. of Glaciology, $\underline{39}$, 199-203, 1993.

Khalil, M. A. K., and R. A. Rasmussen, Climate-induced feedbacks for the global cycles of methane and nitrous oxide, Tellus, 41B, 554-559, 1989.

Khalil, M. A. K., M. J. Shearer, R. A. Rasmussen, Methane sources in China: Historical and current emissions, Chemosphere, 26, 127-142, 1993.

Lamb, H. H., Climate present, past and future, Volume 2 Climate history and the future, Methuen, London and New York, 835 pp., 1977.

McEvedy, C., and R. Jones, Atlas of world population history, New York, pp. 166-167, 1979.

Rasmussen R. A., and M. A. K. Khalil, Atmospheric methane in the recent and ancient atmospheres: concentrations, trends, and interhemispheric gradient, J. Geophys. Res., $\underline{89}$ (D7), 11599-11605, 1984.

Raynaud, D., J. Chappellaz, J. M. Barnola, Y. S Korotkevich and $\mathrm{C}$. Lorius, Climatic and $\mathrm{CH}_{4}$ cycle implications of glacial-interglacial $\mathrm{CH}_{4}$ change in the Vostok ice core, Nature, 333, 655-657, 1988.

Schwander, J., and B. Stauffer, Age difference between polar ice and the air trapped in its bubbles, Nature, $\underline{311}, 45-47$, 1984.

Schwander, J., J.-M., Barnola, C. Andrié, M. Leuenberger, A. Ludin, D. Raynaud and B. Stauffer, The age of the air in the firn and the ice at Summit, Greenland, J. Geophys. Res., 98 (D2), 2831-2838, 1993.

Stauffer, B., G. Fischer, A. Neftel, H. Oeschger, Increase of atmospheric methane recorded in Antatctic ice core, Science, 229, 1386-1388, 1985.

Steele, L. P., E. J. Dlugokencky, P. M. Lang, P. P. Trans, R. C. Martin and K. A. Masarie, Slowing down of the global accumulation of atmospheric methane during the 1980s, Nature, 358, 313-316, 1992.

Thompson, A. M., The oxidizing capacity of the earth's atmosphere: probable past and future changes, Science, 256, 1157-1165, 1992.

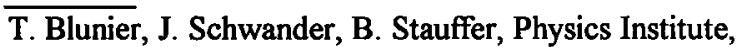
University of Bern, Sidlerstrasse 5, 3012 Bern, Switzerland

J.-M. Barnola, J. A. Chappellaz, T. Desperts, D. Raynaud, CNRS Laboratoire de Glaciologie, BP 96, 38402 St Martin d'Hères Cedex, France

(Received: May 24,1993

Revised: August 17, 1993

Accepted: August 24, 1993) 